\title{
Altered Nerve Terminal Arborization and Synaptic Transmission in Drosophila Mutants of Cell Adhesion Molecule Fasciclin I
}

\author{
Yi Zhong and Jason Shanley \\ Cold Spring Harbor Laboratory, Cold Spring Harbor, New York 11724
}

This work investigates the role of cell adhesion molecules in development of synaptic connections and functions through a genetic approach. Fasciclin I (Fas I) is an insect glycoprotein capable of mediating homophilic cell adhesion. It has been shown that Fas $I$ is expressed in motor nerve axons and terminals that innervate larval body-wall muscles in Drosophila. Immunohistochemical analysis of these motor nerve terminals has revealed that nerve terminal arborization, quantified by the numbers of nerve terminal branches and varicosities, is enhanced in the null mutant fas $/ F E$. In contrast, the number of branches and varicosities are reduced in larvae that overexpress the Fas I molecule resulting from additional copies of the fas / transgene in $P\left(\right.$ fas $\boldsymbol{~}^{+}$) or the chromosome duplication in $D p$ (fas I) mutants. Although arborization is altered, the overall stereotypical pattern of nerve terminal innervation of the body-wall muscle fibers is preserved in all the Fas I mutants examined. The voltage-clamp analysis of excitatory junctional currents (ejcs) at the neuromuscular junction indicates that the amplitude of ejcs is reduced in fas $\mathrm{IE}^{\mathrm{E}}$, but increased in $P\left(\right.$ fas $\left.I^{+}\right)$and $D p($ fas $I)$ compared to that in wildtype larvae. Further electrophysiological analysis shows that the quantal content and the evoked frequency-dependent response are affected in these mutants, indicating a defective presynaptic function in addition to the anatomic abnormality. Therefore, the cell adhesion molecule Fas I may not be essential for target recognition and synaptogenesis at the larval neuromuscular junction, but may play a role in fine-turning nerve terminal arborization and possibly in modifying, directly or indirectly, development of presynaptic functions.

[Key words: fasciclin I, synaptic arborization, synaptic transmission, Drosophila, mutant, cell adhesion]

A large number of cell surface glycoproteins that mediate adhesion of neuron to neuron or to the substratum have been identified in both vertebrates and invertebrates (Edelman and Crossin, 1991; Hortch and Goodman, 1991). Such intercellular mechanical interactions have been shown to affect axon outgrowth and growth cone path-finding (Dodd and Jessell, 1988; Hynes and Lander, 1992; Goodman and Shatz, 1993). The enriched

\footnotetext{
Recived Nov. 16, 1994; revised June 14, 1995; accepted June 19, 1995

We thank Drs. C. S. Goodman and A. Bieber for kindly providing mutant stocks and Fas I antibody, and Drs. C.-F. Wu, N. Wright, and J. Renger for comments on the manuscript. Preliminary experiments of this report were initiated in C.-F. Wu's laboratory at University of Iowa.

Correspondence should be addressed to Yi Zhong, Cold Spring Harbor Laboratory, P.O. Box 100, Cold Spring Harbor, NY 11724.

Copyright (C) 1995 Society for Neuroscience 0270-6474/95/156679-09\$05.00/0
}

presence of cell adhesion molecules in synapses has lead to a speculation that these proteins may also participate in synaptogenesis and synaptic plasticity (Hall and Sanes, 1993). In fact, regulation of the expression of Aplysia cell adhesion molecules, apCAMs, has been shown to be associated with growth of new synaptic connections. This increase in connectivity has been sug gested as a mechanism for long-term synaptic plasticity (Baley et al., 1992; Mayford et al., 1992). It has also been reported in the hippocampus that peptides known to block members of the adhesion-molecule integrin class of matrix receptors can disrupt stabilization of long-term potentiation (Xiao et al., 1991). In addition, the synthesis of neural cell adhesion molecule, NCAM, has been correlated with the establishment of long-term memory in chicks (Scholey et al., 1993). These lines of evidence imply that cell adhesion molecules may provide a molecular mechanism for refinement of synaptic connectivity, hence modifying synaptic function.

In this article, a genetic approach was undertaken which allows a more direct study of how synaptic connectivity and synaptic function may be modified by the expression of cell adhesion molecules in Drosophila. Nerve terminal arborization and synaptic transmission was quantified in neuromuscular junctions of wild-type flies and mutants that either lack or overexpress a specific cell adhesion molecule Fasciclin I (Fas I).

The fas $I$ gene encodes membrane-associated glycoproteins (Zinn et al., 1988; McAllister et al., 1992). The Fas I proteins are expressed on the surface of all PNS neurons and on a subset of CNS neurons as well as on some non-neuronal cells during development of Drosophila (McAllister and Goodman, 1992). They consist of four homologous 150 amino acid domains, and are linked to the external cell surface by a glycosyl-phosyl-phosphatidyl-inositol linkage. Expression of the fas I cDNA in the Drosophila S2 cell line indicates that Fas I is capable of mediating homophilic cell adhesion (Elkins et al., 1990b). Expression of the fas $I$ gene is abolished in the null mutant fas $I^{T E}$ (Elkins et al., 1990a).

In grasshopper embryos, laser inactivation of the Fas I molecules has been shown to disrupt axon fasciculation (Jay and Keshishian, 1990). In Drosophila embryos, the gross nerve structure is not affected in the null fas I mutants (Elkins et al., 1990a). However, axon pathfinding is altered and the commissural axon pathways are often completely absent in the double mutants that lack the expression of both Fas I and the Drosophila homolog of the abl tyrosine kinase (Elkins et al., 1990a). In addition, the fasciculation of a subset of motor neuron axons is disrupted in the double mutants that lack the expression of Fas I and another adhesion molecule Fasciclin III (Chiba et al., 1992). These data indicate the function of Fas I molecules in axon guidance. 
To investigate the role of Fas I in nerve terminal arborization and synaptic function, the larval body-wall neuromuscular preparation was used. This preparation has been extensively characterized immunohistochemically and electrophysiologically (Jan and Jan, 1976a,b; Wu et al., 1978; Ganetzky and Wu, 1983; Johansen et al., 1989; Budnik et al., 1990; Zhong and Wu, 1991a; Atwood et al., 1993; Jia et al., 1993). It provides an excellent model system for the quantitative analysis of nerve terminal arborization and synaptic transmission at identifiable synapses. Immunohistochemical analysis has shown that the projection of motor nerve terminals exhibits a stereotypical pattern of innervation (Johansen et al., 1989). Glutamate is the major excitatory neurotransmitter while several neuropeptides have also been suggested to have a function at these neuromuscular junctions (Jan and Jan, 1976b; Johansen et al., 1989; Zhong and Pena, 1995). It is revealed that the stereotypical pattern of innervation was preserved, while nerve terminal branches and the number of varicosities as well as synaptic function were altered by the fas I mutations.

Thesc results have been reported elsewhere in abstract form (Zhong 1993).

\section{Materials and Methods}

Fly stocks. The wild-type strain Canton-S was used for the characterization of normal nerve terminal arborization and synaptic function. All mutant stocks in the Canton-S background, including fas $I^{T E}, P\left(\right.$ fas $\left.I^{+}\right)$ $D p($ fas $I)$, and $P\left(\right.$ fas $\left.I^{+}\right)$;fas $I^{T E}$, wcre obtaincd from Dr. Goodman's laboratory (at Berkeley). The null mutant fas $I^{I E}$ was generated by the insertion of a large transposon, Ising TE (Ising and Block, 1984). The insertion is found to split the coding region of the fas I gene after amino acid number 35 and abolishes Fas I completely (Elkins et al., 1990a). $P\left(\right.$ fas $\left.I^{+}\right)$is a P-element transformant which carries a $23 \mathbf{~ k b}$ DNA fragment containing all information necessary for correct expression of the fas I gene (Elkins et al., 1990a). The transgene has been localized to the $\mathrm{X}$ chromosome and rescues the fas $I^{I E}$ phenotype (Elkins et al., 1990 a). $D p\left(\right.$ fas I) represents $D p(3 ; 1) 68, y^{2} ; \mathrm{Df}(3) \mathrm{P} 9 / \mathrm{TM} 1 . D p(3 ; 1) 68$ is a duplication with an insertion of 89D-E into the proximal part of the $\mathrm{X}$ chromosome, and the insertion contains the fas $I$ gene. $y^{2}$ is a marker. $D f(3) P 9$ is a deficiency $[D f(3 R) 89 D 9-E 1 ; 89 E 4-5]$ which does not remove the fas I gene (Elkins et al., 1990a) but several other genes covered by $D p(3,1) 68$. Therefore, the fas I gene is duplicated in the $D p$ (fas I) flies. References about the duplication, deficiency, and genetic marker can be found in Lindsley and Zimm (1992). All stocks were reared at room temperature $\left(19-23^{\circ} \mathrm{C}\right)$

Immunohistochemistry. For anti-HRP staining (see Johansen et al., 1989; Budnik et al., 1990; Zhong et al., 1993), late third instar larvae were dissected in saline and then fixed in nonalcoholic Bouin's solution ( $25 \mathrm{ml}$ formalin, $5 \mathrm{ml}$ glacial acetic acid, $75 \mathrm{ml}$ saturated picric acid) for 1-2 hr. The samples were then incubated sequentially with 1:200 anti-HRP (Sigma) and 1:20 HRP-conjugated goat anti-rabbit IgG (Cappel). Immunoreactivity was revealed by the HRP-catalyzed diaminobenzidine reaction. The procedure for anti-Fas I staining is similar to that for anti-HRP staining. The fixed samples were incubated with sequentially 1:2 monoclonal anti-Fas I (provided by Drs A. Bieber of Purdue and C. Goodman of Berkeley) and 1:20 HRP-conjugated goat anti-mouse IgG (Cappel). Immunoreactivity was revealed by the HRPcatalyzed diaminobenzidine reaction.

Electrophysiological recordings. Electrophysiological analysis of the larval body-wall neuromuscular preparation has been described previously (Jan and Jan, 1976a,b; Wu et al., 1978; Ganetzky and Wu, 1983; Zhong and $\mathrm{Wu}, 1991 \mathrm{a})$. Briefly, third instar larvae were dissected in $\mathrm{Ca}^{2+}$-free saline that contained $\mathrm{NaCl}(128 \mathrm{mM}), \mathrm{KCl}(2 \mathrm{mM})$, sucrose (35.5 mM), $\mathrm{MgCl}_{2}(4 \mathrm{mM})$, EGTA $(0.5 \mathrm{mM})$, Hepes $(5 \mathrm{mM}$, buffered at $\mathrm{pH}$ 7.1). For recordings, different concentrations of $\mathrm{CaCl}_{2}$ were used, as specified in each experiment. Electrical stimulation of motor axons was delivered by suction electrode. The data were collected by either Polaroid camera from an oscilloscope or by a chart recorder. Some of the data were also recorded on videotapes. The amplitude of ejcs or mejes was measured by hand directly from current traces recorded by the camera or chart recorder. The rise time of mejcs was determined by playing back the data recorded in videotapes to an oscilloscope. All data were collected from muscle fiber 12 using an Axoclamp 2A (Axon). All recordings were carried out at room temperature $\left(19-23^{\circ} \mathrm{C}\right)$.

\section{Results}

Alteration of nerve terminal arborization in fas I mutants

The segmental body-wall muscle fibers in Drosophila larvae are organized in a regular pattern (Crossley, 1978; Johansen et al., 1989). Within individual identifiable fibers, motor axon terminals exhibit distinct branching patterns (Johansen et al., 1989; Budnik et al., 1990). These motor nerve terminals have been extensively characterized with anti-HRP immunohistochemical staining (Johansen et al., 1989; Budnik et al., 1990; Zhong et al., 1992), which specifically labels insect neurons (Jan and Jan, 1982).

Since arborization is strongly activity dependent (Budnik et al., 1990; Zhong et al., 1992), motor nerve terminals innervating muscle tibers 12 and 13 in segments 3 to 5 were first examined in the fas $I$ mutants. These include the null mutant fas $I^{T E}$, a transformant $P\left(\right.$ fas $\left.I^{+}\right)$carrying a normal fas $I$ transgene (Elkins et al., 1990a) and a chromosome duplication $D p($ fas $I$ ) in which a fragment of DNA covering the fas I gene has been translocated from chromosome 3 to the X chromosome (see Fly Stocks for details). A representative example of anti-HRP immunohistochemical staining of motor nerve terminals in normal larvae is shown in Figure $1 A$. As compared to wild-type larvae, nerve terminal arborization was enhanced in the null mutant fas $I^{E E}$ and was reduced in $P\left(\right.$ fas $\left.I^{+}\right)$and $D p($ fas $I)$ larvae with overexpression of Fas I molecules (Fig. $1 A$ ). Such a conclusion is strengthened by the statistical analysis shown in Figure $1 B$. Based on similarities in the pattern of innervation, the numbers of nerve terminal branches and varicosities on muscle fibers 12 and 13 are pooled together as parameters that describe nerve terminal arborization on the two fibers. A branch is defined as a terminal process containing at least two varicosities. Statistically, the numbcrs of branches and varicosities on muscle fibers 12 and 13 are significantly increased in the fas $I^{T E}$ mutant. In contrast, the numbers are decreased in both $P\left(\right.$ fas $\left.I^{+}\right)$and $D p($ fas I) mutants (Fig. 1B)

Under light microscopy, varicosities on muscle fibers 12 and 13 can be classified into type 1 and type 2 (Johansen et al., 1989). Type 1 are those with larger diameters (1-5 $\mu \mathrm{m})$ distributed mainly along thicker primary axons while type 2 are smaller ones $(<1 \mu \mathrm{m})$ distributed along thin higher order processes. However, it is difficult to separated these two types completely when the data were documented by camera lucida tracing. The fas $I$ mutations appear to alter primarily the number of the type 2 varicosities. To determine whether the type 1 terminals were also affected, we examined muscle fibers 6 and 7 . Only the type 1 varicosities are found on these fibers (Johansen et al., 1989). The number of varicosities counted from the both fibers was decreased significantly in the both $P\left(\right.$ fas $\left.^{+}\right)$and $D p($ fas $I)$ mutant larvae, but was similar in the fas $I^{T E}$ null mutant compared to that in the wild-type larvae (Fig. $2 A, B$ ). Therefore, The type 1 terminals are altered only in larvae which overexpress Fas I. The number of branches was not quantified since it was not easy to define branches in terminals arborized on muscle fibers 6 and 7 (see Fig. 2A).

To illustrate the extent and variability of branching in different genotypes, isomorphic representations were compiled (Fig. 3), each depicting the branching pattern of the single primary process that showed the highest number of branches in either mus- 
A

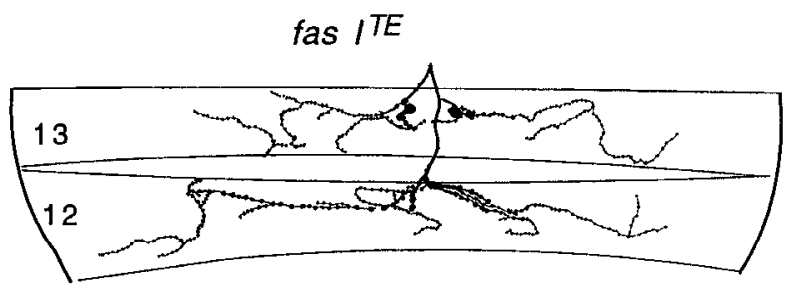

normal

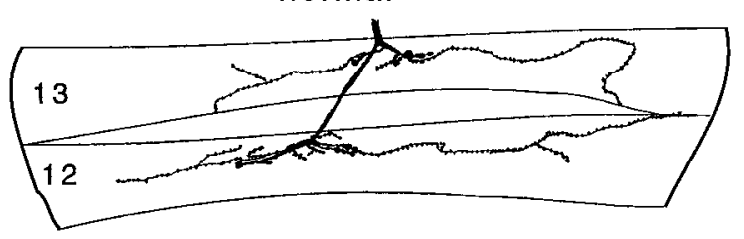

$D p($ fas I)

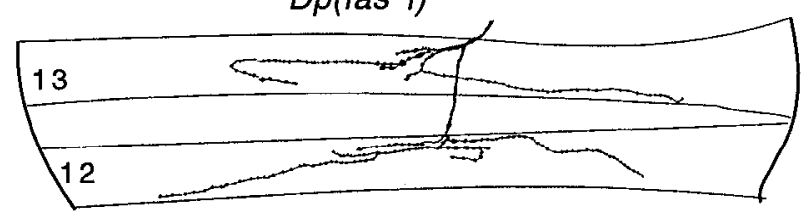

B

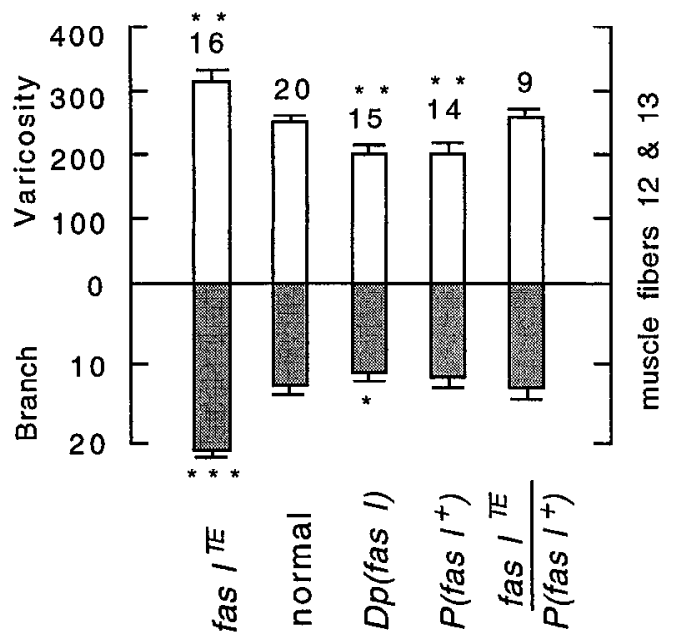

Figure 1. Effects of fas I mutations on motor nerve terminal arborization on muscle fibers 12 and 13. $A$, Camera lucida tracings of antiHRP staining of motor axon terminals on muscle fibers 12 and 13 of abdominal segment 3 in third instar larvae of Drosophila. For anatomical analysis, data were obtained only from muscles 12 and 13 in abdominal segment 3 . The fine neurites in the tracings presented here are thickened for clarity and this partially masks some of smaller varicosities. Individual varicosities were more clearly resolved in photomicrographs (see, for example, Budnik et al., 1990). Scale bar, $50 \mu \mathrm{m}$. B, Statistical analysis of the effect of the fas $I$ mutations on nerve terminal branches and varicosities. The total numbers of varicosities and branches represent the sum of the numbers of both muscle fibers 12 and 13 in one hemisegment. A branch is defined as a terminal process containing at least two varicosities. The mean and SEM in each genotype are presented for the number of larvae indicated. For each batch of samples, we used muscles 12 and 13 in each larva from the same side of segment 3 and, only if prevented by damage or unsatisfactory staining, the other side would be used. Mutant data are compared to those obtained from wild-type larvae with $t$ test and statistically significant differences as indicated $(*, p<0.05 ; * *, p<0.01 ; * * *, p<0.005)$.
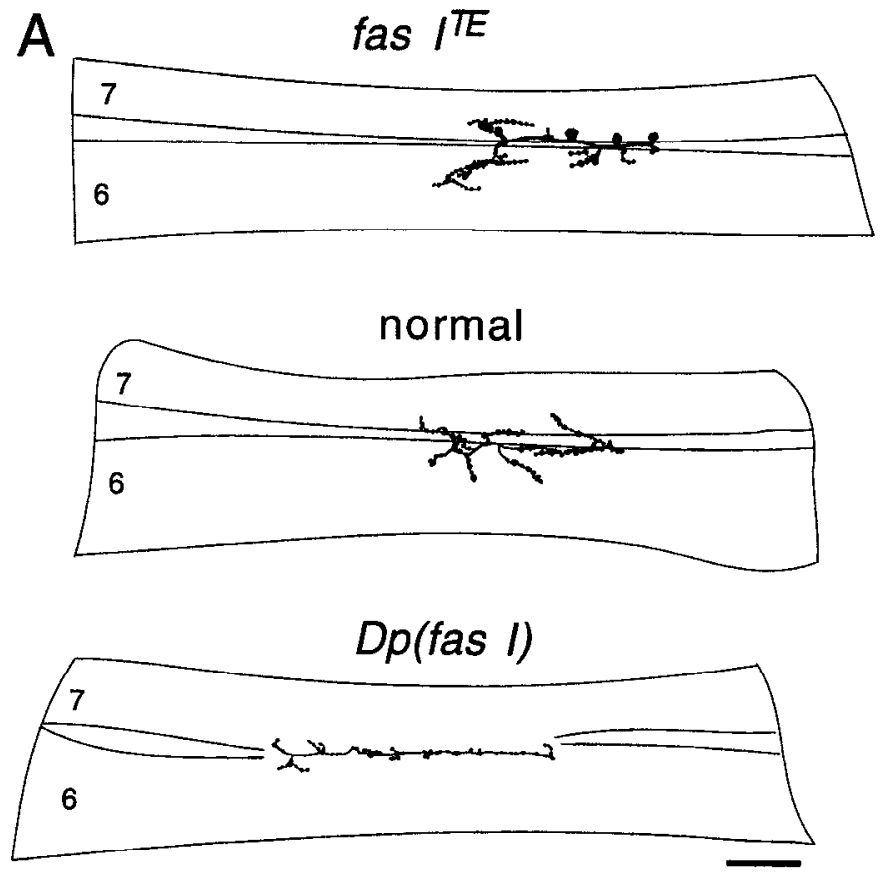

B

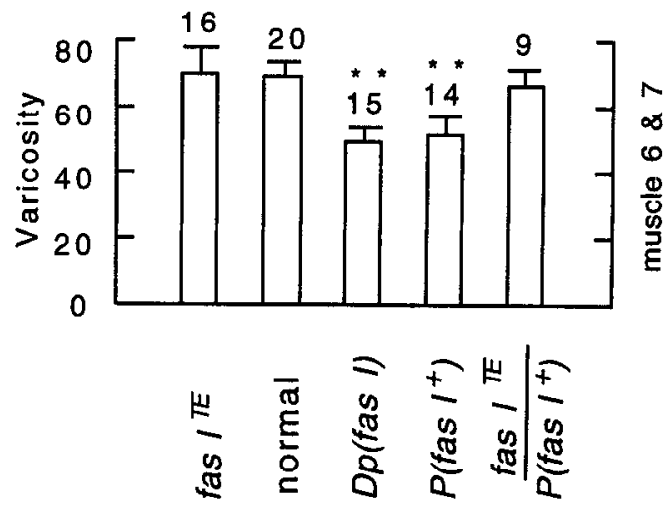

Figure 2. Effects, of fas I mutations on motor nerve terminal arborization on muscle fibers 6 and 7. A, Camera lucida tracings of anti-HRP staining of motor axon terminals on muscle fibers 6 and 7 of abdominal segment 3 in the third instar larvae of Drosophila. As compared to Figure 1, the stereotypic pattern of innervation on muscle 6 and 7 is very different from those in muscle fibers 12 and 13 . Scale bar: $50 \mu \mathrm{m}$. $B$. Statistical analysis of the effect of the fas $I$ mutations on nerve terminal branches and varicosities. The number of varicosities represents the sum of the numbers of both muscle fibers 6 and 7 in one hemisegment. The mean and SEM in each genotype are presented for the number of larvae indicated. For each batch of samples, we used muscles 6 and 7 in each larva from the same side of segment 3 and, only if prevented by damage or unsatisfactory staining, the other side would be used. Mutant data are compared to those obtained from wildtype larvae with $t$ test and statistically significant differences as indicated $(* *, p<0.01)$.

cle fibers 12 or 13 in individual larvae. Evidently, branching is more extensive in the fas $I^{T E}$ mutant as indicated by more higher order branches (Fig. 3).

In order to determine whether this effect results from an abnormal expression of Fas I, the following experiments were carried out. First, the $P($ fas $I+)$; fas $I^{T E}$ transgenic mutant was examined. Previous Western blot analysis has indicated that the lack of expression of the fas $I$ gene in the null mutant fas $I^{T E}$ is 
fas $I^{T E}$<smiles>CC(C)C(C)C(C)(C)C(C)(C)C</smiles><smiles>CC(C)C(C)C</smiles><smiles>CC(C)CC(C)C1C(C)C(C)C2C(C)CC(C)C1C2C(C)CC(C)C</smiles><smiles>CC(C)C(C)C(C)(C)C</smiles>

入 1<smiles>CC1CC(C)C1C</smiles><smiles>CCC(C)(C(C)C(C)C)C(C)C(C)C</smiles><smiles>CC(C)C1(C)C(C)C(C)C1(C(C)C)C(C)C</smiles><smiles>CC(C)CC(C)C</smiles><smiles>CC(C)CC(C)C</smiles>

Figure 3. Isomorphic representations of the branching pattern. Each representation illustrates the branching pattern of the single process that showed the highest number of branches in either muscle fiber 12 or 13 . More extensive branching is seen in the fas $I^{T E} \mathrm{mu}-$ tant. Only data from the first 10 larvae during sampling are presented.

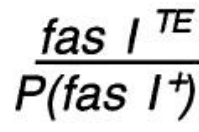<smiles>CCCCCC(C)C</smiles><smiles>CC(C)CC(C)C(C)C</smiles><smiles>CC(C)CC(C)C(C)C</smiles><smiles>CC(C)C(C)C</smiles>

\section{$D p($ fas $リ$ サ}

rescued by the fas $I^{+}$transgene in $P\left(\right.$ fas $\left.I^{+}\right)$;fas $I^{T E}$ transgenic mutant flies (Elkins et al., 1990). Consistent with this biochemical study, abnormal nerve terminal arborization in the fas $\Gamma^{T E}$ mutant was also rescued by the fas $I^{+}$transgene. The numbers of branches and varicosities in the $P\left(\right.$ fas $\left.I^{+}\right)$; fas $I^{T E}$ transgenic mutant become similar to those seen in wild-type larvae (Figs. $1 B, 2 B)$. Second, anti-Fas I immunohistochemical analysis was performed. Fas I immunoreactivity was found in both type 1 and type 2 motor nerve terminals (Fig. 4). Representative examples of Fas I immunoreactivity in muscle fibers 6,12 , and 13 are presented (Fig. 4). It is also expressed in nerve terminals innervate other muscle fibers (not shown). Both type 1 (pointed by single arrowhead) and type 2 (see Fig. $4 D$; by three arrowheads in line) varicosities were stained. Fas I immunoreactivity at motor nerve terminals was absent in the fas $I^{T E}$ mutant (Fig. $4 F, H$ ). This mutant phenotype is rescued by the fas $I^{+}$transgene in the
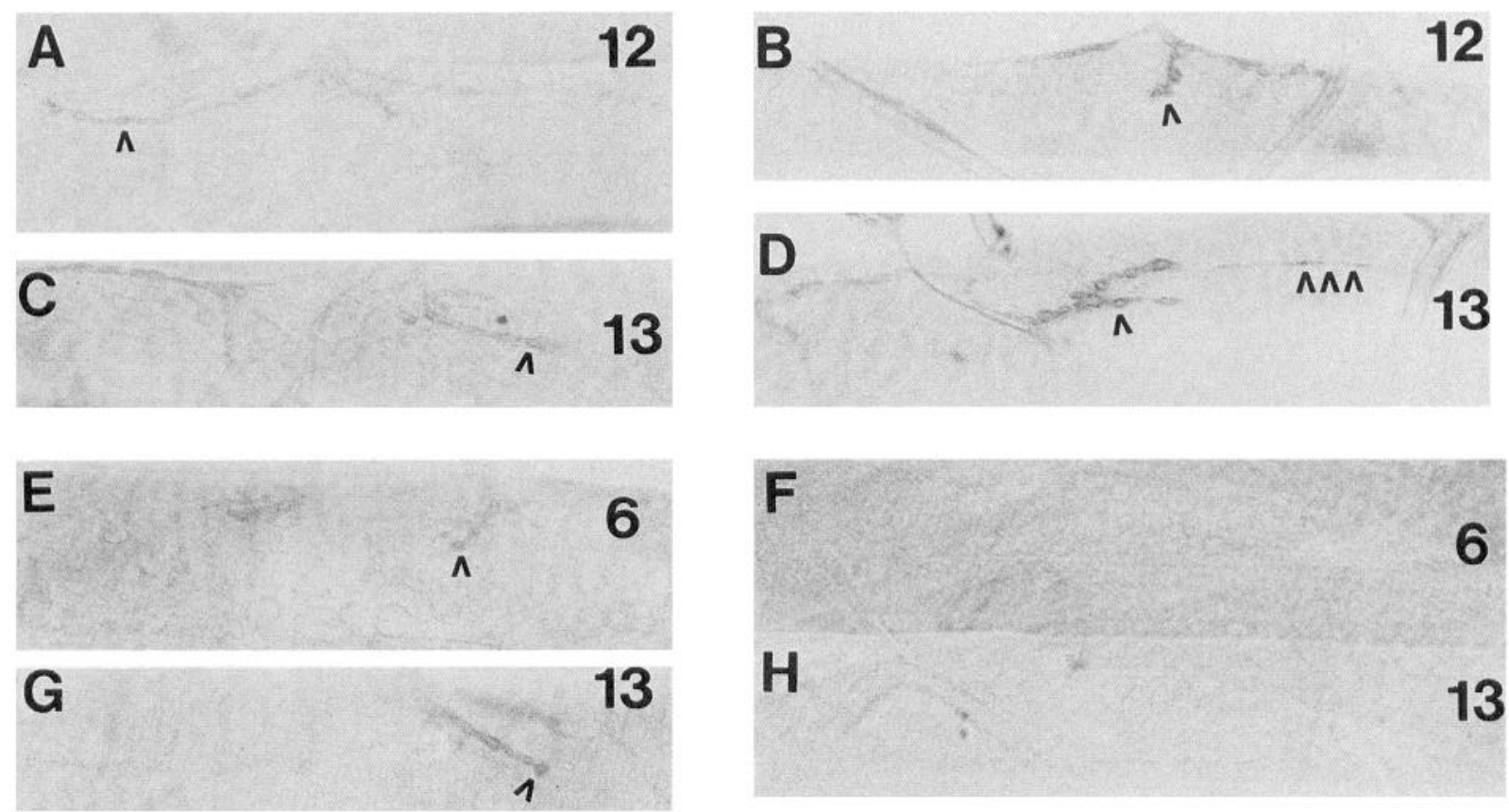

Figure 4. Fas I immunoreactivity at body-wall motor nerve terminals of third instar larvae. Fas I immunoreactivity, revealed by a monoclonal antibody, was found at all motor nerve terminals that innervate body-wall muscle fibers of third instar larvae. Both large-sized type 1 (pointed by a single arrowhead) and small-sized type 2 (pointed by three arrowheads in a line) varicosities exhibit immunoreactivity. Since Fas I immunoreactivity is weak, the staining in small-sized varicosities is not represented well in the photograph but is clear under the microscope. $A, C$, and $E$, representative examples of Fas I immunoreactivity in different normal muscle fibers as specified by the numbers. $B$, Fas $I$ immunoreactivity is enhanced in $P\left(\right.$ fas $\left.I^{+}\right)$transgenic larvae. $D$, Fas $I$ immunoreactivity is enhanced in $D p($ fas $I)$. $F$ and $H$, Fas $I$ immunoreactivity is abolished in the null mutant fas $I^{T E}$. G, Fas I immunoreactivity of the null mutant phenotype is rescued by a fas $\mathrm{I}^{+}$transgene in the $P\left(\right.$ fas $\left.I^{+}\right)$;fas $I^{T E}$ allele. The numbers indicate specific muscle fibers according to the nomenclature of Crossley (1978). 


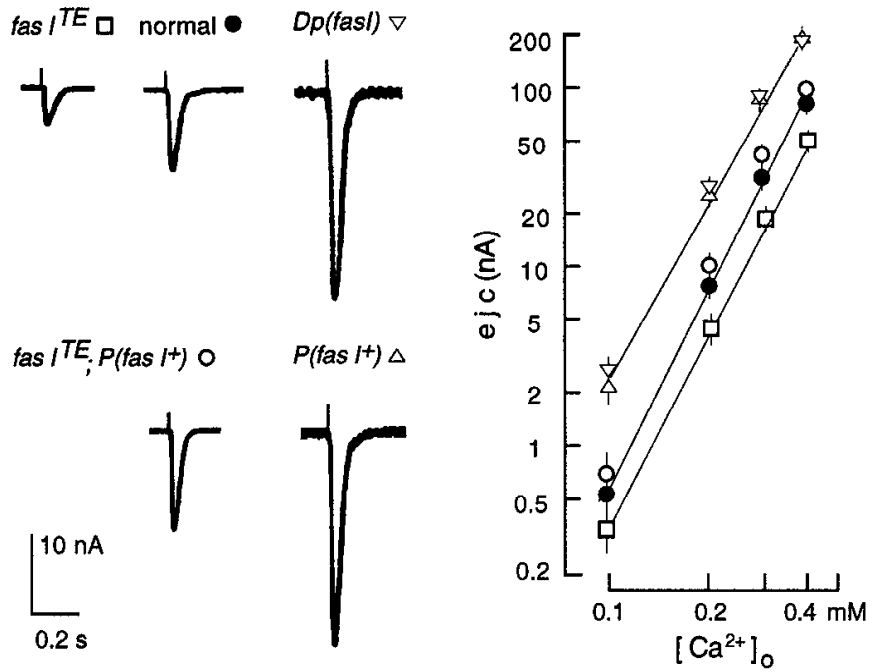

Figure 5. Effects of fas I mutations on ejcs and their $\mathrm{Ca}^{2+}$ dependence. Current traces on the left are representative examples of evoked excitatory junctional currents (ejcs) recorded at $0.2 \mathrm{~mm}$ external $\mathrm{Ca}^{2+}$. Plots on the right show ejc amplitude as a function of external $\mathrm{Ca}^{2+}$ concentration. Each data point represents the mean \pm SEM of 14-50 responses (including failures) from each of six to eight fibers in different larvae. For all recordings, the muscle membrane was clamped at a holding potential of $-80 \mathrm{mV}$. The maximum extent of deviation from the holding potential $(-80 \mathrm{mV})$ in these experiments was about $4 \mathrm{mV}$.

$P\left(\right.$ fas $\left.I^{+}\right)$;fas $I^{T E}$ transgenic mutant (Fig. $4 G$ ). As expected, Fas I immunoreactivity appears more intense in both $P\left(\right.$ fas $\left.I^{+}\right)$and $D p($ fas $I$ ) larvae compared to that seen in wild-type larvae (see Figs. $4 A$ vs $B$ and $C$ vs $D$ ). Although the intensity of immunoreactivity was not quantified, the difference was detectable visually and was consistent among five pairs of wild-type versus $D p$ (fas $I$ ) larvae (one pair is presented in Fig. $4 A, B$ ) and three pairs of wild-type versus $P\left(\right.$ fas $I^{+}$) larvae (one in Fig. $4 C, D$ ), with each pair processed for staining together.

To summarize, the data described above suggest that elimination of the expression of the fas I gene may lead to an expansion in motor nerve terminal projections while the overexpression of the fas I gene may result in a reduction in nerve terminal arborization. 'I'his result prompted an examination of neuromuscular transmission in these mutants.

\section{Altered synaptic transmission in fas I mutants}

The two-microelectrode voltage-clamp method was used to record excitatory junctional currents (ejcs) from muscle fiber 12 in segments 3-5. As mentioned earlier, glutamate is the major excitatory neurotransmitter at the larval neuromuscular junction (Jan and Jan, 1976b; Johansen et al., 1989). Each supra-threshold stimulation of the motor nerve fiber evokes glutamate-mediated ejcs. The muscle fiber was clamped at $-80 \mathrm{mV}$ to prevent activation of voltage-gated ion channels (Zhong and Wu, 1991a). Therefore, transmitter release evoked at different external $\mathrm{Ca}^{2+}$ concentrations by nerve stimulation was accurately reflected by the ejc amplitude. The $\mathrm{Ca}^{2+}$ dependence of transmitter release was altered in fas I mutants.

The evoked ejc amplitude was increased in the both $P\left(\right.$ fas $\left.I^{+}\right)$ and $D p$ (fas $I$ ) larvae with overexpression of Fas I. Conversely, ejcs were smaller in mutant fas $I^{T E}$ larvae (Fig. 5). Again, cjes in the $P\left(\right.$ fas $\left.I^{+}\right)$;fas $I^{T E}$ double mutant appeared to be normal (Fig. 5), indicating that the altered ejcs seen in the mutants may result from an abnormal expression of the Fas I molecule. Spon-
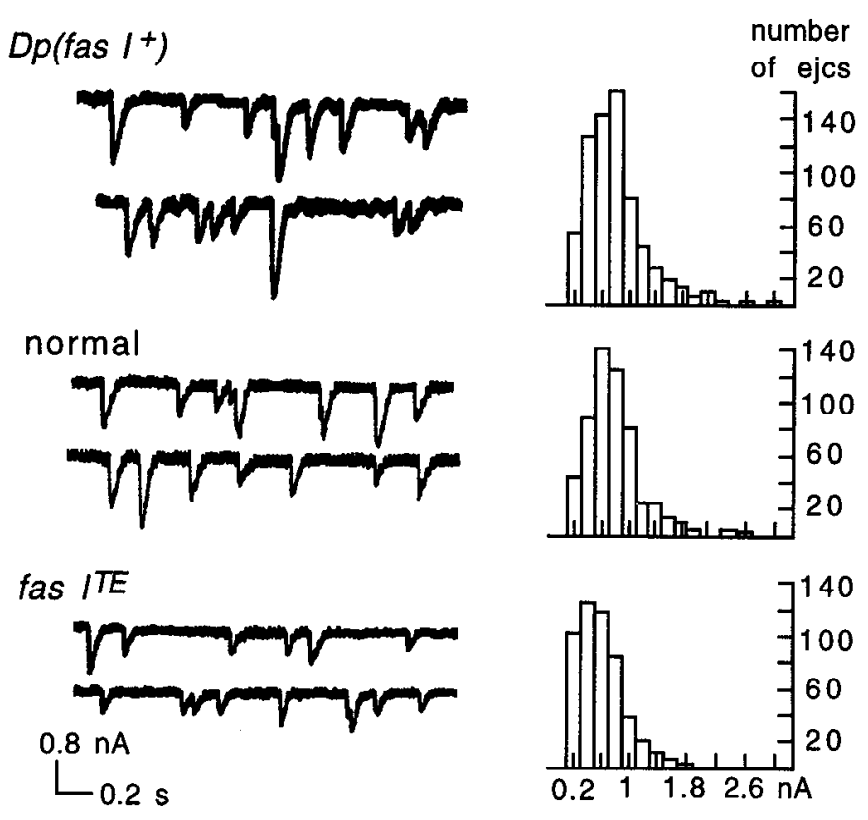

Figure 6. Effect of fas I mutations on quantal size. Spontaneous miniature ejcs (mejcs) were recorded at $0.2 \mathrm{mM} \mathrm{Ca}^{2+}$. Data presented in the histogram (right) are pooled from recordings from four to five muscle fibers, about 100 mejes from each fibcrs, of each genotype (see Table 1).

taneous miniature ejcs (mejcs) caused by the release of a single synaptic vesicle were recorded for further examination of the cellular mechanisms that contribute to the altered neuromuscular transmission in the fas I mutants. The quantal size, the averaged amplitude of mejcs, is considered to be mainly influenced by postsynaptic properties (Katz, 1969). Analysis of the quantal size (Fig. 6) indicated that the distribution of mejcs was shifted in the fas $I^{T E}$ larvae from that seen in wild type larvae. The distribution was similar among the $D p($ fas $I$ ), wild type (Fig. 6), $P\left(\right.$ fas $I^{+}$), and $P\left(\right.$ fas $\left.I^{+}\right)$; fas $I^{Y E}$ (not shown) larvae. More smaller mejcs were recorded while some extremely large-sized mejcs were absent in the fas $I^{T E}$ mutants (Fig. 6). The reduction in quantal size is statistically significant in fas $I^{T E}$ as compared to that of the quantal size in the wild type, $D p($ fas $I), P\left(\right.$ fas $\left.I^{+}\right)$, or $P\left(\right.$ fas $\left.I^{+}\right)$; fas $I^{T E}$ larvae (Table 1$)$. However, there is no significant difference among wild type, $D p($ fas $I), P\left(\right.$ fas $\left.I^{+}\right)$, or $P\left(\right.$ fas $\left.I^{+}\right)$;fas $I^{T E}$ larvae (Table 1). Yet, the rise time (10\% to $\left.90 \%\right)$ of mejcs remaincd similar in wild type $(0.39 \pm 0.06 \mu \mathrm{sec})$ and fas $\Gamma^{T E}$ $(0.41 \pm 0.08 \mu \mathrm{sec})$ averaged from 20 recordings of two muscle fibers for each genotype.

Since mejcs are not significantly altered in the $D p($ fas $I)$ and

Table 1. Effect of fas I mutations on the quantal size

\begin{tabular}{llll} 
Genotype & $n$ & \multicolumn{2}{l}{ mejc (mean $\pm \mathrm{SD}) t$ test } \\
\hline fas $I^{E}$ & 5 & $0.58 \pm 0.09$ & $<0.01$ \\
Wild type & 6 & $0.78 \pm 0.08$ & \\
$D p($ fas $I)$ & 5 & $0.86 \pm 0.12$ & $>0.05$ \\
$P\left(\right.$ fas $\left.I^{+}\right)$ & 5 & $0.80 \pm 0.09$ & $>0.05$ \\
$P\left(\right.$ fas $\left.I^{+}\right) ;$fas $I^{T E}$ & 4 & $0.76 \pm 0.11$ & $>0.05$
\end{tabular}

$n$, The number of muscle fibers examined. About 100 mejcs were recorded from each fiber. mejc (mean \pm SD), The size of each mejc is averaged first in single fibers. $t$ test, The statistical significance $(\alpha / 2)$ of differences in the mejc size between wild type and each mutant. 


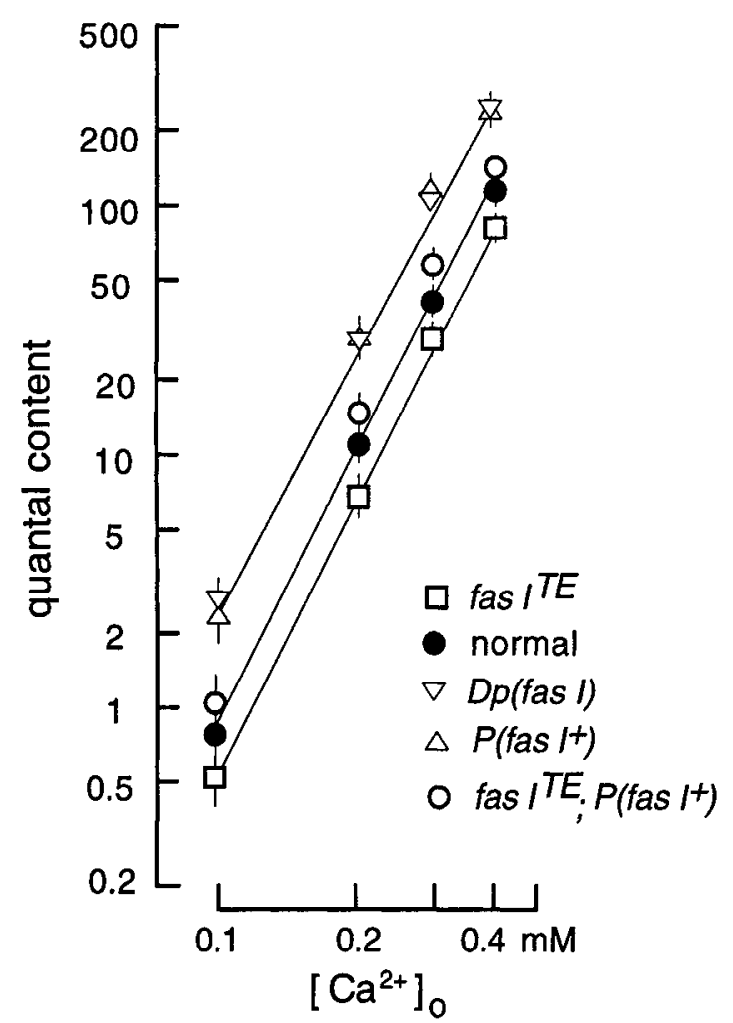

Figure 7. Effects of fas I mutations on $\mathrm{Ca}^{2+}$ dependence of the quantal content. The quantal content is determined by a division of the mean amplitude of ejcs by the quantal size. The mean amplitude of ejcs has been presented in Figure 5. The quantal size has been presented in the Table 1. The Figure shows that the quantal content is increased in $D p($ fas $I)$ and $P\left(f a s I^{+}\right)$but decreased in the fas $I^{T E}$ larvae.

$P\left(\right.$ fas $\left.I^{+}\right)$larvae, the increased ejcs in these mutants may result from a presynaptic mechanism. This is supported by an analysis of the quantal content. The number of synaptic vesicles (quantal content) released in a synaptic response is thought to be a measure of presynaptic function. The quantal content can be determined by a division of the mean amplitude of evoked ejcs by the quantal size. Based on the mejcs size, the $\mathrm{Ca}^{2+}$ dependence of the quantal content was plotted in Figure 7. The quantal content was apparently increased in the $D p($ fas $I)$ and $P\left(\right.$ fas $\left.I^{+}\right)$ larvae but slightly reduced in the fas $I^{T E}$ mutant at four $\mathrm{Ca}^{2+}$ concentrations examined.

The quantal content can also be derived independently by analysis of synaptic failure. At $0.1 \mathrm{mM} \mathrm{Ca}^{2+}$, a large fraction of nerve stimuli failed to trigger transmitter release in the fas $I^{T E}$ mutant and wild-type larvae (Table 2). But the failure was higher in fas $\Gamma^{T E}$. In contrast, it was rare to see any failure in both $P(f a s$ $I^{+}$) and $D p($ fas I) (Table 2). Calculated on the basis of the failure rate, the quantal content is decreased in fas $I^{T E}$ but strongly increased in $P\left(\right.$ fas $\left.I^{+}\right)$and $D p($ fas $I)$ compared to that observed in the wild-type larvae (Table 2). This is consistent with the result derived earlier by the ejcs size (comparing Table 2 with the quantal content at $0.1 \mathrm{Ca}^{2+} \mathrm{mM}$ in Fig. 7).

The possibility that failure in $0.1 \mathrm{mM} \mathrm{Ca}^{2+}$ resulted from an inability to evoke action potentials in motor axons was largely excluded by the following observations. (1) Motor axons were stimulated by a 1.5 or $2 \times$ threshold voltage. (2) To confirm that the voltage is high enough to evoke consistent motor axon firing in both fas $I^{T E}$ and wild-type larvae, the same voltage was tested at $0.4 \mathrm{mM} \mathrm{Ca}^{2+}$ after data collection at $0.1 \mathrm{mM} \mathrm{Ca}^{2+}$. At the
Table 2. Quantal content in fas I mutants

\begin{tabular}{llrl} 
Genotype & $n$ & \multicolumn{1}{l}{$N / N$} & $m$ \\
\hline fas $I^{T E}$ & 5 & $125 / 210$ & 0.5 \\
Wild type & 6 & $86 / 212$ & 0.9 \\
$D p($ fas $I)$ & 5 & $7 / 115$ & 2.8 \\
$P\left(\right.$ fas $\left.I^{+}\right)$ & 4 & $4 / 114$ & 3.6 \\
$P\left(\right.$ fas $\left.I^{+}\right) ;$fas $I^{T E}$ & 5 & $67 / 187$ & 1.0
\end{tabular}

$n$, The number of muscle fibers examined. About 20-60 responses $(N)$ were recorded from each fiber. $N$, The total number of synaptic responses recorded for each genotype. $N_{o}$ The total number of synaptic failures for each genotype. $m$, The quantal content $\left[\operatorname{In}\left(N / N_{\mathrm{r}}\right)\right]$.

higher $\mathrm{Ca}^{2+}$ concentration, each stimulus evoked a muscle response.

Therefore, alteration of quantal content in fas $I$ mutants is confirmed by two independent approaches. Such a difference probably results from an abnormal expression of the Fas I proteins because quantal content measured from the $P\left(\right.$ fas $\left.I^{+}\right)$;fas $I^{T E}$ double mutant appeared to be more closer to normal than those from either $P\left(\right.$ fasI $\left.^{+}\right)$or fas $I^{r E}$ single mutants (Fig. 7, Table 1).

A change in the quantal content among different genotypes may arise from a number of sources. Examination of the high frequency stimulation-evoked response implied that altered excitability in the fas $I$ mutants may contribute. Each supra-threshold stimulation of motor axons evoked a single, fast glutamategated muscle response in wild-type larvae (Fig. 8). Such an oneto-one relationship was maintained even in response to $20 \mathrm{~Hz}$ stimulation in the wild-type larvae. However, when 8 or $16 \mathrm{~Hz}$ stimuli were applied to the either $D p($ fas $I)$ or $P\left(\right.$ fas $\left.I^{+}\right)$larvae, an abnormal spontaneous discharge could often be induced (Fig. 6). The initial responses following a train of $8 \mathrm{~Hz}$ pulses in these larvae appeared to be normal, that is, each stimulation triggering a single ejcs. After several normal-like responses, spontaneous ejcs were observed (Fig. 8). Even after ceasing the stimulation, the induced spontaneous transmitter release could continue for a minute or longer. 15 out of 24 muscle fibers from $D p($ fas I) and $P\left(\right.$ fas $\left.I^{+}\right)$larvae produced abnormal spontaneous discharges. In a few of $D p($ fas $I)$ and $P\left(\right.$ fas $\left.I^{+}\right)$muscle fibers (3 out of 24), spontaneous discharges were observed (Fig. $8 B$ ). There were no wild-type or fas $I^{T E}$ larvae (24 fibers) as well as the $P\left(\right.$ fas $\left.I^{+}\right)$;fas $I^{T E}$ double mutant (11 fibers) that showed such a hyperexcitable response.

Previous studies have suggested that the spontaneous discharge is likely to be the result of spontaneous firing generated in the motor axons due to hyperexcitability (Ganetzky and Wu, 1982, 1983). Hyperexcitability induced by either application of a $\mathrm{K}^{+}$channel blocker, DTX, or by mutations in the eag gene, which reduce $\mathrm{K}^{+}$current, also leads to spontaneous discharges (Ganetzky and Wu, 1983; Wu et al., 1989). Thus, abnormal spontaneous discharges observed in fas $I$ mutants provide indirect evidence that excitability may be altered in motor nerve terminals of these mutants.

\section{Discussion}

In the above experiments, we have examined nerve terminal arborization and synaptic transmission in mutants that either lack expression or overexpress the cell adhesion molecule Fas I. Two observations support a conclusion that altered nerve terminal arborization and synaptic transmission in these mutants is due 


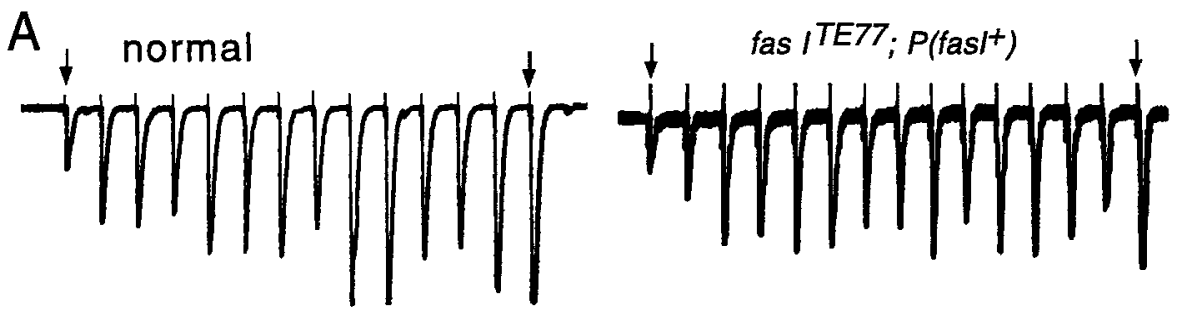

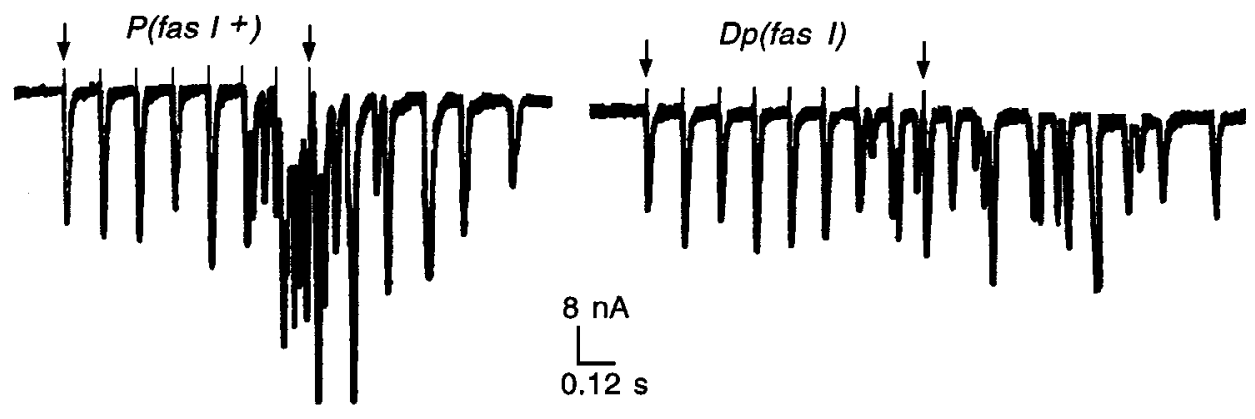

B
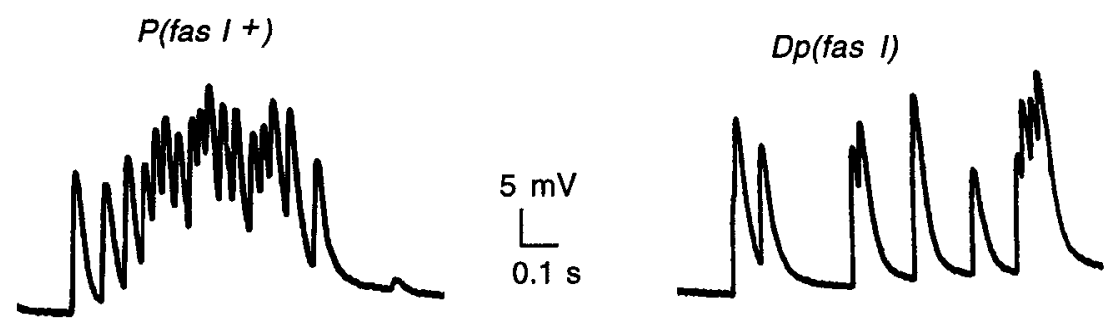

Figure 8. Abnormal hyperexcitability in larvae with overexpression of Fas I proteins. A, Evoked ejcps. Each single supra-threshed stimulation of motor axons evoked a single glutamate-gated muscle response in normal larvae and fas I mutant larvae. When a train of 8 $\mathrm{Hz}$ stimulation is delivered to either $D p($ fas $I)$ or $P\left(\right.$ fas $\left.I^{+}\right)$larvae, abnormal spontaneous ejcs could be induced. The initial response in these larvae appears to be normal, but spontaneous ejcs were induced (bottom panel) following several normal-like responses. Even after ceasing the stimulation, the induced spontaneous transmitter release could continue for a minute or longer. The abnormal response observed in $P$ (fas $\left.I^{+}\right)$transformants was rescued in the double mutant fas $\Gamma^{T E} ; P\left(\right.$ fas $\left.I^{+}\right)$. Arrows point to the beginning and the end of evoked responses. $B$, Abnormal spontaneous discharges were observed occasionally in some muscle fibers of $D p($ fas $I)$ or $P\left(\right.$ fas $\left.I^{+}\right)$larvae. Recordings were obtained at $0.2 \mathrm{~mm} \mathrm{Ca}{ }^{2+}$. to an abnormal expression of the Fas I proteins. First, the phenotype observed in the null mutant fas $I^{T E}$ is opposite to that in $D p($ fas $I)$ and $P\left(\right.$ fas $\left.I^{+}\right)$(see Figs. 1-5). Thus, the cellular phenotypes correlate well with the molecular phenotypes: no Fas I in fas $I^{T E}$ but more Fas 1 in $D p($ fas $I)$ and $P\left(\right.$ fas $\left.I^{+}\right)$. Second, the defects seen in the either fas $I^{T E}$ or $P\left(\right.$ fas $\left.I^{+}\right)$larvae can be rescued in the $P\left(\right.$ fas $\left.I^{+}\right)$; fas $I^{T E}$ double mutant. Such observations are consistent in the immunohistochemical reactivity (Fig. 4), nerve terminal arborization (Figs. 1-3), and synaptic transmission (Figs. 5-8, Table 1). Thus, the analysis of these mutants demonstrates that an alteration in the expression of the Fas I molecules can influence the development of nerve terminal arborization as well as synaptic function.

\section{Cell adhesion molecules in modifying synaptic connection}

The presence of cell adhesion molecules in developing and mature synapses has lead to the speculation that cell adhesion molecules may be involved in synaptogenesis (Hall and Sanes, 1993), in addition to their possible roles in axon outgrowth and axon guidance. Analysis of fas I mutants indicates that this cell adhesion molecule appears not to be absolutely required in synaptogenesis because synapses are formed in these mutants and for motor axon guidance since the stereotypical pattern of innervation is preserved in the null fas $I$ mutant (see Figs. 1 and 2; also see Chiba et al., 1992). Instead, this molecule may be important for modifying or fine-tuning nerve terminal arborization. An increase in the expression of the Fas I proteins tends to reduce nerve terminal branches and the number of varicosities while the lack of expression tends to enhance nerve terminal arborization (see Figs. 13 ).

Arborization in the examined motor nerve terminals has been shown to be neural-activity dependent. Hyperexcitability induced by ion-channel mutations or by increasing temperature at which flies are raised results in enhanced nerve terminal arborization, quantified by the numbers of nerve terminal branches and varicosities (Budnik et al., 1990; Zhong and Wu, 1991b). Neural activity probably exerts its influence on nerve terminal arborization via the cAMP cascade (Zhong et al., 1992). However, the molecules that are regulated by the cAMP cascade and directly affect nerve terminal arborization remain to be identified. Since the fas $I$ mutation-induced changes in nerve terminal arborization are very similar to those seen in hyperexcitability mutants, it raises a possibility that regulation of the expression of the fas $I$ gene may contribute to neural activity-dependent synaptic plasticity.

It is interesting to note that excitability appears to be enhanced but arborization reduced in the $D p($ fas $I)$ and $P\left(\right.$ fas $\left.I^{+}\right)$mutants (see Figs. 1 and 6). This observation does not contradict the possibility that Fas I may contribute to activity-dependent arborization. In fact, it lends further supporting evidence. Enhanced excitability may affect arborization via regulation of the Fas I expression. Therefore, arborization can not be increased in the $D p($ fas $I)$ and $P\left(\right.$ fas $\left.I^{+}\right)$larvae by enhanced excitability since excitability may fail to reduce the Fas I expression sufficiently because of the additional copies of the fas $I$ gene introduced in these flies. This possibility can be tested if arborization is ex- 
amined in mutants with combinations of $D p($ fas $I)$ or $P\left(\right.$ fas $\left.I^{+}\right)$ and hyperexcitability mutations. Such work is in progress.

The detailed mechanism underlying modification of synaptic connections by Fas I awaits to be investigated. Fas I appears only to be expressed in motor axons and not on the muscle surface (see Fig. 4; also see Chiba et al., 1992). Since the Fas I proteins are capable of mediating homophilic cell adhesion in a transfected Drosophila S2 cell line (Elkins et al., 1990b), one possibility is that Fas I mediates axon-axon interaction, instead of axon-muscle interaction. Therefore, more nerve terminal branches and thus more synaptic connections are formed due to defasciculation of axon bundles in the Fas $I^{I E}$ mutant. Conversely, less branches are formed due to stronger fasciclation in $D p($ fas $I)$ and $P\left(\right.$ fas $\left.I^{+}\right)$. However, it can not be excluded that Fas I may also mediate heterophilic adhesion. In fact, several adhesion molecules have been shown to mediate both homophilic and heterophilic interactions (Felsenfeld et al., 1994).

\section{Cell adhesion molecules in the development of synaptic function?}

A number of studies have correlated the expression of cell adhesion molecules with long-term changes in synaptic transmission (Xiao et al., 1991; Bailey et al., 1992; Mayford et al., 1992). The present work demonstrates that synaptic transmission could be altered by mutations at the fas $I$ locus. Interestingly, the change in nerve terminal arborization in the fas $I$ mutants is conversely associated with the alteration in synaptic response measured as the amplitude of ejcs (see Figs. 1 and 5). A close examination of the data presented offers a few clues on how synaptic transmission may be affected in these mutants.

Reduced quantal size (see Fig. 6) in the fas $\Gamma^{E}$ mutants implies that postsynaptic function may be affected by the mutation. A simple explanation of such an observation could be that the density of glutamate receptors, which gate mejcs, is lower in the fas $I^{T E}$ mutant. However, according to the "saturating disk model" (Land et al., 1980), a reduction in receptor density should lead to an increase in the rise time of mejcs if the synapse function near the receptor saturation. Such an increase in the rise time is not observed in fas $I^{T E}(0.41 \pm 0.08 \mathrm{msec})$ compared to that in wild type $(0.39 \pm 0.06 \mathrm{msec})$. This discrepancy may be explained as to that the neuromuscular junction does not function near the condition of the receptor saturation as suggested by Kidokoro and Nishkawa (1994). In summary, other evidence may be required to conclude that the reduced quantal size in the fas $I^{T E}$ mutant reflects an effect of the mutation on postsynaptic function.

The fas I mutations appears to affect mainly presynaptic function. This is indicated by changes in the $\mathrm{Ca}^{2+}$ dependence of the quantal content and abnormal spontaneous firing induced by high frequency stimulation in the fas $I$ mutants (see Table 1; Figs. 7, 8). Both observations are consistent with the idea that excitability is enhanced in the $D p($ fas $I)$ and $P\left(\right.$ fas $\left.I^{+}\right)$motor nerve terminals. First, the abnormal spontaneous discharge induced by high frequency stimulation is an indication of enhanced excitability in the motor axons. Such an interpretation is supported by previous analyses (Ganetzky and Wu, 1982, 1983; Wu et al., 1989) of the effects of $\mathrm{K}^{+}$channel mutants and $\mathrm{K}^{+}$ channel blockers (see description in the Results). Second, the increased quantal content seen in the $D p($ fas $I)$ and $P\left(\right.$ fas $\left.I^{+}\right)$ larvae might also be interpreted as a consequence of enhanced excitability which allows a greater $\mathrm{Ca}^{2+}$ influx with each evoked firing. The larger $\mathrm{Ca}^{2+}$ influx in turn results in release of more synaptic vesicles or a much lower chance of synaptic failure compared to that seen in the wild-type or fas $I^{\text {TE }}$ larvae. However, it cannot be excluded that other mechanisms may also contribute to the altered presynaptic function, such as the releasing machinery affected developmentally by the overexpression of the Fas I proteins.

Altered presynaptic function may indicate that Fas I is important for development of presynaptic functions. For instance, $\mathrm{Ca}^{2+}$ channels are clustered near the releasing sites (Llina as et al., 1992) and Fas I might be a factor involved in defining channel localization. Or it may be just simply due to a mechanism which compensates functionally for the structural change induccd by abnormal expression of the Fas I molecules. Further examination of the fas $I$ and other related mutants may provide insight into whether and how cell adhesion molecules are involved in development of synaptic functions.

\section{References}

Atwood HL, Govind CK, Wu C-F (1993) Differential ultrastructure of synaptic terminals on ventral longitudinal abdominal muscles in Drosophila larvae. J Neurobiol 24:1008-1024.

Bailey CH, Chen M, Keller F, Kandel ER (1992) Serotonin-mediated endocytosis of apCAM: An early step of learning-related synaptic growth in Aplysia. Science 256:645-649.

Budnik V, Zhong Y, Wu C-F (1990) Morphological plasticity of motor axons in Drosophila mutants with altered excitability. J Neurosci 10: 3754-3768.

Chiba A, Chang TN, Keshishian H (1992) Double mutation of fasciclin I and fasciclin III causes erroneous growth cone behavior of Drosophila. Soc Neurosci Abstr 18:536.7.

Crossley CA (1978) The morphology and development of the Drosophila muscular system. In: The genetics and biology of Drosophila, Vol 2b (Ashburner, Wright, eds). New York: Academic.

Dodd J, Jessell TM (1988) Axon guidance and the patterning of neuronal projections in vertebrates. Science 242:692-699.

Edelman GM, Crossin KL (1991) Cell adhesion molecules: implications for a molecular histology. Annu Rev Biochem 60:155-190.

Elkins T, Hortsch M, Bieber AJ, Snow PM, Goodman CS (1990b) Drosophila fasciclin I is a novel homophilic adhesion molecule that along with fasciclin III can mediate cell sorting. J Cell Biol 110: $1825-1832$.

Elkins T, Zinn K, McAllister L, Hoffmann FM, Goodman CS (1990) Genetic analysis of a Drosophila neural cell adhesion molecule: interaction of fasciclin I and abelson tyrosine kinase mutations. Cell 60:565-575.

Felsenfeld DP, Hynes MA, Skoler KM, Furley AJ Jessell TM (1994) TAG-1 can mediate homophilic binding, but neurite outgrowth on TAG-1 requires an L1-like molecule and b1 integrins. Neuron 12: 675-690.

Ganetzky B, Wu CF (1982) Drosophila mutants with opposite effects on nerve excitability: genetic and spatial interactions in repetitive firing. J Neurophysiol 47:501-514.

Ganetzky B, Wu C-F (1983) Neurogenetic analysis of potassium currents in Drosophila: synergistic effects on neuromuscular transmission in double mutants. J Neurogenet 1:17-28.

Goodman CS, Shatz CJ (1993) Developmental mechanisms that generate precise patterns of neuronal connectivity. Cell $72 /$ Neuron 10(Suppl):77-98.

Hall ZW, Sanes JR (1993) Synaptic structure and development: The neuromuscular junction. Cell 72/Neuron 10(Suppl):99-121.

Hortsch M, Goodman CS (1991) Cell and substrate adhesion molecules in Drosophila. Annu Rev Cell Biol 7:505-557.

Ising G, Block K (1984) A transposon as a cytogenetic marker in Drosophila melanogaster. Mol Gen Genet 196:6-16.

Jan LY, Jan YN (1976a) Properties of the larval neuromuscular junction in Drosophila melanogaster. J Physiol (Lond) 262:189-214.

Jan LY, Jan YN (1976b) L-Glutamate as an excitatory transmitter at the Drosophila larval neuromuscular junction. J Physiol (Lond) 262: 215-236.

Jan LY, Jan YN (1982) Antibodies to horseradish peroxidase as specific 
neuronal markers in Drosophila and grasshopper embryos. Proc Natl $\Lambda$ cad Sci US $\Lambda$ 72:2700 2704.

Jay DG, Keshishian H (1990) Laser inactivation of fasciclin I disrupts axon adhesion of grasshopper pioneer neurons. Nature 348:548-550.

Jia X-X, Gorczyca M, Budnik V (1993). Ultrastructure of neuromuscular junctions in Drosophila: comparison of wild type and mutants with increasing excitability. J Neurobiol 24:1025-1044.

Johansen J, Halpern ME, Johansen KM, Keshishian H (1989) Stereotypic morphology of glutamatergic synapses on identified muscle cells of Drosophila larvae. J Neurosci 9:710-725.

Katz B (1969) The release of neural transmitter substances Liverpool: Liverpool UP.

Keshishian H, Chiba A (1993) Neuromuscular development in Drosophila: insights from single neurons and single genes. Trends Neurosci $16: 278-283$

Lindsley DL, EH Grell (1968) Genetic variations of Drosophila melanogaster. Carnegie Institution of Washington, Publication No. 627.

Lindsley DL, Zimm GG (1992) The genome of Drosophila melanogaster. San Diego: Academic.

Llinás R, Sugimori M, Silver RB (1992) Microdomains of high calcium concentration in a presynaptic terminal. Science 256:677-679.

Mayford M, Barzilai A, Keller F, Schacher S, Kandel ER (1992) Modulation of an NCAM-related adhesion molecule with long-term synaptic plasticity in Aplysia. Science 256:638-644.

McAllister L, Goodman CS (1992) Dynamic expression of the cell adhesion molecule fasciclin I during embryonic development in Drosophila. Development 115:267-276.

McAllister L, Rehm EJ, Goodman CS, Zinn K (1992) Alternative splicing of micro-exons creates multiple forms of the insect cell adhesion moleculc fasciclin I. J Ncurosci 12:895-905.
Scholey AB, Rose SPR, Zamani MR, Bock E, Schachner M (1993) A role for the neural cell adhesion molecule (NCAM) in a late, consolidation phase of glycoprotein synthesis 6 hours following passive avoidance training of the young chick. Neuroscience 55:499-509.

Wu C-F, Ganetzky B, Jan LY, Jan Y-N, Benzer S (1978) A Drosophila mutant with a temperature-sensitive block in nerve conduction. Proc Natl Acad Sci USA 75:4047-4051.

Wu CF, Tsai M-C, Chen M-L, Zhong Y, Singh S, Lee CY (1989) Actions of dendrotoxin on $\mathrm{K}^{+}$channels and neuromuscular transmission in Drosophila melanogaster, and its effects in synergy with $\mathrm{K}^{+}$channel-specific drugs and mutations. J Exp Biol 147:21-41.

Xio P, Bahr BA, Staubli U, Vanderklish PW, Lynch G (1991) Evidence that matrix recognition contributes to stabilization but not induction of LTP. Neuroreport 2:461-464.

Zhong Y (1993) Mutational analysis of the cell adhesion molecule fasciclin $I$ in the development of synaptic function in Drosophila. Soc Neurosci Abstr 19:526.4.

Zhong Y, Pena L (1995) A novel synaptic transmission mediated by a PACAP-like neuropeptide in Drosophila. Neuron 14:527-536.

Zhong Y, Wu C-F (1991a) Altered synaptic plasticity in Drosophila memory mutant with altered cAMP cascade. Science 251:198-201.

Zhong Y, Wu C-F (1991b) Suppression of activity-dependent synaptic plasticity in nerve terminal arborization by memory mutant rutabaga in Drosophila. Soc Neurosci Abstr 17:418.19.

Zhong Y, Budnik V, Wu C-F (1992) Synaptic plasticity in Drosophila memory and hyperexcitability mutants: role of cAMP cascade. J Neurosci 12:644-651.

Zinn K, McAllister L, Goodman CS (1988) Sequence analysis and neuronal expression of fasciclin I in Grasshopper and Drosophila. Cell 53:577-587. 